\title{
INDUCED CHANGES IN THE CIRCULATION IN CONSTRICTIVE PERICARDITIS
}

\author{
BY \\ RICHARD H. LYONS AND C. SIDNEY BURWELL \\ From the Department of Medicine of the Harvard Medical School and the Medical Service of the Peter Bent \\ Brigham Hospital, Massachusetts, U.S.A. \\ Received September 21, 1945 \\ It is accepted that constrictive pericarditis curtails the normal excursion of the ventricles. \\ This leads to a diminution in the output of the heart per beat, and, in spite of an elevated pulse \\ rate, to a diminution also in the output of the heart per minute. Nearly all the studies of the \\ circulation in patients with pericardial obstruction (Beck and Griswold, 1930; Burwell and \\ Strayhorn, 1932; Beck and Cushing, 1934; Maltby, 1934; Burwell and Flickinger, 1935 ; \\ Burwell and Blalock, 1938; Stewart, Heuer, Deitrick, Crane, Watson, and Wheeler, 1938) \\ have been carried out under standard or basal conditions. The purpose of this paper is to \\ place on record some additional measurements of the circulation under standard conditions, \\ and also to report a series of studies of patients with constrictive pericarditis made under \\ various special circumstances. These special studies include observations of the changes in \\ the circulation associated with alterations in the blood volume, the pulse rate, and the venous \\ pressure.
}

\section{Presentation of Patients}

The observations were made during the study and treatment of two patients, now to be described.

Case 1. G. M. was born in 1900. In April 1931 he developed right-sided pleurisy with effusion. His rather mild disability disappeared after removal of the fluid by tapping, and for several months he considered himself well. In November 1931 he was found to have a left-sided pleural effusion. There was fever, and active tuberculosis of the left apex was demonstrated by X-ray. At about this time he first noticed that his ankles were swollen and that he became short of breath in climbing a short flight of stairs. Under sanatorium care he improved. In 1932 he had another period of fever, this time associated with swelling of the abdomen, and he entered the Peter Bent Brigham Hospital. Here he was found to be a slight young man, a little pallid,.but with a bluish tinge to the nail beds. The area of cardiac dulness was enlarged, the heart rate rapid, and the sounds distant. No murmurs were heard. The arterial blood pressure was 124/60. The abdomen was distended by ascites, and the liver was felt $3 \mathrm{~cm}$. below the costal margin. The fluoroscope revealed the signs of apical fibrosis of both lungs and a considerably enlarged cardiac shadow said to be of water-bottle shape. The amplitude of the cardiac excursion was described as good.

Abdominal paracentesis removed 1800 c.c. of fluid in which tubercle bacilli were demonstrated by guinea-pig inoculation. As fluid slowly reaccumulated he complained of præcordial discomfort and a sense of drawing and tightness under the sternum which was worse on inspiration. After four months he had shown no improvement. The arterial pressure had declined to $98 / 64$, the liver was larger, and the veins more distended. Fluoroscopic examination revealed the heart shadow to be no longer enlarged, and the amplitude of the cardiac excursion was now described as poor.

He went back to the sanatorium and after some months of rest in bed was much better. He was then permitted graded activity and in April 1934 was discharged.

From April 1934 until resection of the pericardium in 1938, his condition changed but little. He 
was comfortable at rest but suffered dyspnœa and weakness on exertion, even such slight exertion as walking on the level at the usual pace. This severe limitation of exercise tolerance prevented him from performing the manual labour on which his livelihood depended.

Our own observations began in December 1935, and we have been in touch with him ever since. On any visit before the operation of 1938 he would display the following physical signs: the face was full and suffused; the feet and hands were cold to the touch and often clammy; there was a little cyanosis of the nail beds and an exaggerated longitudinal curvature of the nails. The neck veins were distended and firm and the venous pressure (see later) was always above the normal limits. The cardiac dulness was no longer as large as it had been, but measured only $4.5 \mathrm{~cm}$. to the right and $6.5 \mathrm{~cm}$. to the left. The dulness did not shift with change in the patient's position. The heart rate was more rapid than normal, the rhythm was regular, the sounds faint, and there were no murmurs nor additional heart sounds. The arterial pressure was 108/90 and there was slight paradoxical fluctuation. The lungs (in which there were changes consistent with healed fibrous tuberculosis) showed no moist rales. The vital capacity was moderately reduced (usually it was about 2400 c.c.). The liver was usually to be felt 3 or $4 \mathrm{~cm}$. below the rib margin. Ascites was not present at this time.

It was apparent that we were dealing with constrictive pericarditis, the cause of which was tuberculosis and the result of which was an obstruction to blood flow of only moderate degree. (This will be shown clearly in the measurements reported later). Because his symptoms were mild and apparently non-progressive, operation was not then advised. Instead he was given graded exercise in an attempt to improve his general condition. He followed the regime faithfully but over the years seemed, if anything, to lose ground rather than to gain it. His limitations, although slight, were disabling, and in 1938 it was decided to advise treatment by operation.

On February 10, 1938, under avertin-ether anæsthesia, Dr. E. C. Cutler performed a pericardiolysis. At operation an interesting situation was found which $\mathrm{wm}_{\mathrm{s}}$ described in the operative note as follows: "When the pleura on the left was pushed aside it was noted that in the lower portion of the field there was a vigorous ventricular contraction while the upper portion of the field was motionless and muscular contraction was palpated as if through a thick sheet. The pericardium was opened and freed from the heart muscle down to the phrenic nerve on the left and to the right into a stiff area of diseased tissue. This area led into broken-down cheesy material quite characteristic of tuberculosis of the pericardium. Directly under the pericardium on the upper portion of the right ventricle lay a sheet of very hard fibrous tissue which limited the muscular movements beneath it. This epicardial scar was carefully shaved away and as it was removed there was marked improvement in the ventricular contraction, so much so that the muscle actually bulged into the field."

On microscopic examination the tissue removed was found to be dense hyalinized collagen with granulation tissue both old and recent. No tubercle bacilli were seen and no evidence of active tuberculosis was found. The pathologist's impression was that the tissue could be classified as healed tuberculous pericardium.

Almost immediately after the operation there was a change in the physical appearance of the patient. The suffused appearance of the face disappeared, the cyanosis of the nail beds was replaced by a normal pink colour, and the hands were no longer cold and clammy. At this time the venous pressure was within normal limits. After a fortnight, however, the pressure in the veins increased and it remained elevated for the next four months. During this time the patient experienced progressive gain in comfort though there was little laboratory evidence to suggest it. His ability to perform physical work improved, as did his sense of strength and well-being. Gradually, over months, his strength grew and his venous pressure fell. He became able to walk on the level without discomfort, climb hills or stairs without difficulty, and before long returned to his former occupation.

One more tuberculous chapter was written in his history in 1939 when he developed bone tuberculosis involving the right femur.

Since 1935 he has been under frequent observation in the laboratory. Many of the observations made there apply to the description of the course of his disease. They are reported in a subsequent section of this paper.

Case 2. (The course of this patient's illness has already been described by Burwell and Ayer (1941) in another connection; only a summary account will be presented here.) A. B. was a Lithuanian labourer of 54. In January 1938 he began to suffer from cough and coryza. A few weeks later he experienced dyspnœa on exertion, followed shortly by dyspnœa at rest, by orthopnœa, and by œdema of the ankles. When he entered the hospital on March 12, 1938, the heart rate was rapid, the rhythm regular, the pulse small. The heart was not enlarged and no murmurs were heard. The neck veins were visibly distended; the liver edge was $5 \mathrm{~cm}$. below the rib margin; there were signs of fluid in both pleural cavities; and there was slight œedema of the ankles. A friction rub was audible over the præcordium and in the left axilla. The arterial blood pressure was $100 / 70 \mathrm{~mm}$; the venous blood pressure was $210 \mathrm{~mm}$. of water. At fluoroscopic examination the excursion of the left heart border 
was considered to be less than normal and there was no visible movement of the right border. An electrocardiogram showed low voltage, inverted T II and T III, and a normal lead IV.

Some improvement in comfort followed a few days of hospital care, during which time his chest: was tapped and he received digitalis and mercurial diuretics. When he had lost some 16 pounds. of fluid by various routes he could lie flat without dyspnœea and the vital capacity was found to be 3100 c.c., but the peripheral venous pressure remained elevated. The temperature rarely rose above $99^{\circ} \mathrm{F}$. and was usually within limits considered normal.

A diagnosis of constrictive pericarditis was made. Tuberculosis was considered the cause of the pericarditis since the pleural fluid was found to contain tubercle bacilli by guinea-pig inoculation. Operation was advised. After nearly three months, during which time his disability continued and his venous pressure remained high, the patient decided to accept this advice. Dr. Cutler performed the operation in July 1938. He found a tough fibrous pericardium about $3 \mathrm{~mm}$. thick closely applied to the heart. The entire anterior portion of this was excised and the heart was observed to pulsate more vigorously.

The venous pressure (Lyons, Kennedy, and Burwell, 1938) fluctuated somewhat during the first week after operation, but after that was never above $105 \mathrm{~mm}$., i.e. it was well within normal limits. The evidences of congestion disappeared and it was considered that operation had relieved the mechanical obstruction to the entrance of blood into the heart. An account of his further course and of his tragic death from constrictive pleuritis a few weeks later has been recorded elsewhere (Burwell and Ayer, 1941).

These two patients, then, suffered from tuberculous pericarditis with constriction of the heart. Both had disability that was not extreme, and both were co-operative and interested participants in our studies of them. Tiney were thus particularly suitable for the type of observation now to be described.

\section{Methods OF STUdY}

Accepted methods were used for measuring various aspects of the circulation. The cardiac output was determined by the acetylene method, using the three-sample modification described by Gröllman, Friedman, Clark, and Harrison (1933). The venous pressure was measured by the direct method as applied by Lyons, Kennedy, and Burwell (1938). The blood volume was measured by the method of Gibson * and Evelyn (1938). Circulation time was the arm-to-tongue time indicated by the intravenous injection of $4-5$ c.c. of sodium dehydrocholate.

Most of the observations on both patients were made while they were ambulatory. The patient would come to the laboratory in the fasting state, and after preliminary determinations of vital capacity he would rest in a reclining chair for 45 to 60 minutes before the estimation of the cardiac output was made. Following the determination of the cardiac output he was placed on an examining table for the measurement of venous pressure, circulation time, arterial blood pressure, and blood volume. When the patient did not have a determination of the cardiac output he rested on the examining table at least 15 minutes before the venous pressure was measured.

The observations made may be divided into two groups: those made under standard conditions before and after operation; and those made before, during, and after induced alterations in the circulation.

\section{ObSERvations Under STANDARd Conditions}

Measurements of the venous pressure, blood volume, and cardiac output made under basal conditions before and after operation, are recorded in Table I and illustrated in Fig. 1 for Case 1, and recorded in Table II for Case 2. A persistently elevated venous pressure and a persistently low cardiac output per minute and per beat were present in both patients prior to operation. The blood volume in Case 1 was above the normal values. In Case 2 it was within the normal range based on height. It may be that the considerable emaciation and muscle atrophy in this patient affected the estimation of the normal values from his height or weight.

* We are indebted to Dr. J. G. Gibson II for his co-operation in making the measurements of the blood volume. 
TABLE I

Observations on Case 1

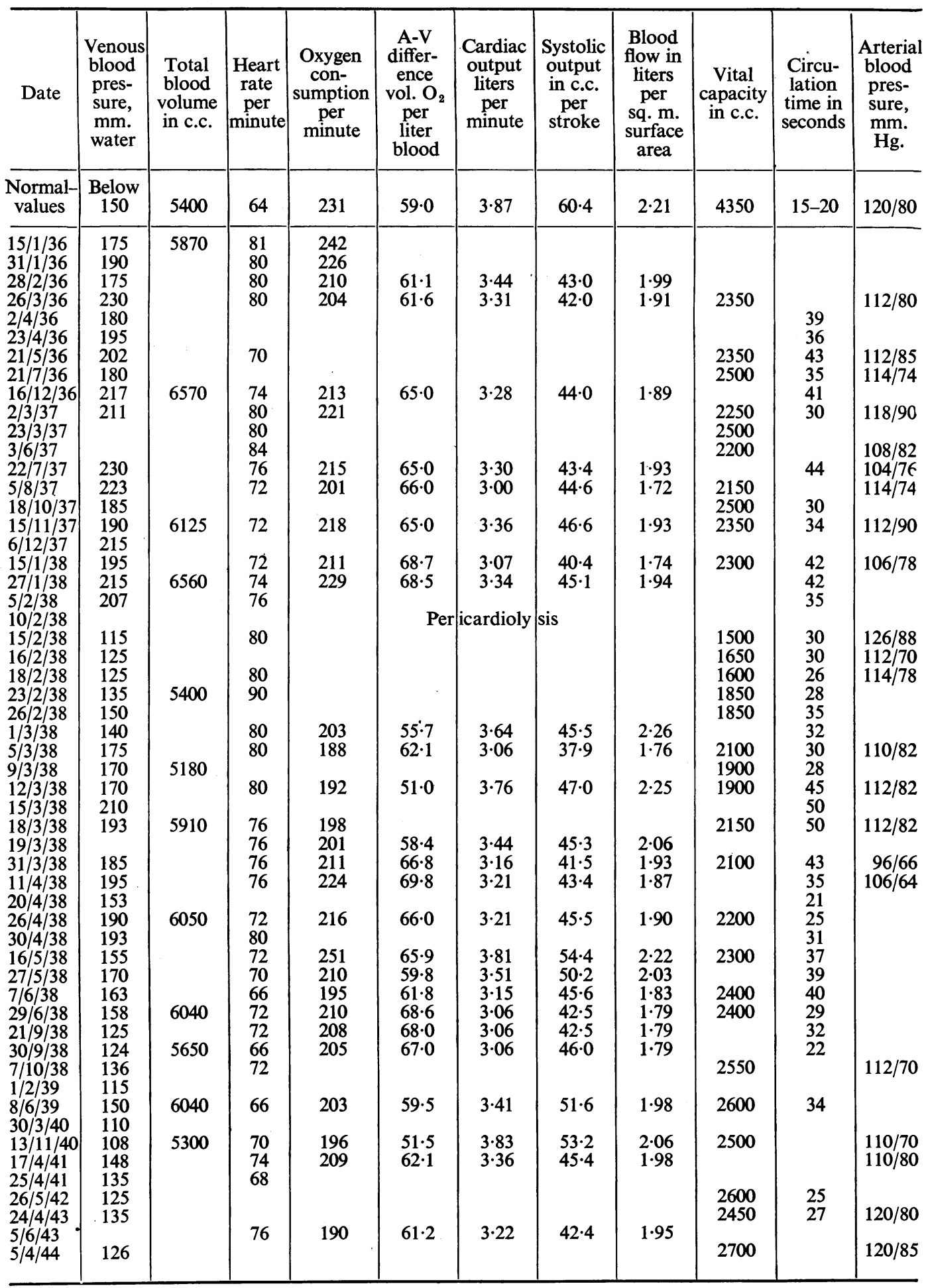


TABLE II

ObServations ON CASE 2

\begin{tabular}{|c|c|c|c|c|c|c|c|c|c|c|c|}
\hline Date & $\begin{array}{l}\text { Venous } \\
\text { blood } \\
\text { pres- } \\
\text { sure, } \\
\text { mm. } \\
\text { water }\end{array}$ & $\begin{array}{c}\text { Total } \\
\text { blood } \\
\text { volume } \\
\text { in c.c. }\end{array}$ & $\begin{array}{c}\text { Heart } \\
\text { rate } \\
\text { per } \\
\text { minute }\end{array}$ & $\begin{array}{c}\text { Oxygen } \\
\text { con- } \\
\text { sumption } \\
\text { per } \\
\text { minute }\end{array}$ & $\begin{array}{c}\text { A-V } \\
\text { differ- } \\
\text { ence } \\
\text { vol. } \mathrm{O}_{2} \\
\text { per } \\
\text { liter } \\
\text { blood }\end{array}$ & $\begin{array}{c}\text { Cardiac } \\
\text { output } \\
\text { liters } \\
\text { per } \\
\text { minute }\end{array}$ & $\begin{array}{c}\text { Systolic } \\
\text { output } \\
\text { in c.c. } \\
\text { per } \\
\text { stroke }\end{array}$ & $\begin{array}{l}\text { Blood } \\
\text { flow in } \\
\text { liters } \\
\text { per } \\
\text { sq. m. } \\
\text { surface } \\
\text { area }\end{array}$ & $\begin{array}{c}\text { Vital } \\
\text { capacity } \\
\text { in c.c. }\end{array}$ & $\begin{array}{l}\text { Circu- } \\
\text { lation } \\
\text { time in } \\
\text { seconds }\end{array}$ & $\begin{array}{l}\text { Arterial } \\
\text { blood } \\
\text { pres- } \\
\text { sure, } \\
\text { mm. } \\
\mathrm{Hg} \text {. }\end{array}$ \\
\hline $\begin{array}{l}\text { Normal } \\
\text { values }\end{array}$ & 150 & 5400 & 64 & 212 & $59 \cdot 0$ & $3 \cdot 68$ & $57 \cdot 7$ & $2 \cdot 2$ & 4250 & $15-20$ & $120 / 80$ \\
\hline $\begin{array}{l}21 / 3 / 38 \\
28 / 3 / 38 \\
30 / 3 / 38 \\
1 / 4 / 38 \\
3 / 4 / 38 \\
5 / 4 / 38 \\
12 / 4 / 38 \\
14 / 4 / 38 \\
20 / 4 / 38 \\
21 / 4 / 38 \\
10 / 5 / 38 \\
24 / 5 / 38 \\
26 / 5 / 38 \\
14 / 6 / 38 \\
1 / 7 / 38 \\
8 / 7 / 38 \\
13 / 7 / 38 \\
14 / 7 / 38 \\
15 / 7 / 38 \\
16 / 7 / 38 \\
18 / 7 / 38 \\
20 / 7 / 38 \\
28 / 7 / 38 \\
8 / 8 / 38 \\
30 / 8 / 38\end{array}$ & $\begin{array}{l}255 \\
250 \\
237 \\
185 * \\
232 \\
245 \\
\\
213 \\
265 \dagger \\
205 \ddagger \\
195 \S \\
208 \\
283 \| \\
265 \\
\\
220 \\
205 \\
155 \\
125 \\
110 \\
122 \\
150 \\
141\end{array}$ & $5070 *$ & $\begin{array}{c}74 \\
72 \\
72 \\
70^{*} \\
72 \\
76 \\
82 \\
78 \\
100 \dagger \\
88_{+}^{\ddagger} \\
88 \S \\
88 \\
90 \| \\
88 \\
\\
88 \\
86 \\
88 \\
92 \\
94\end{array}$ & $\begin{array}{l}186 \\
191 \\
197 \\
193^{*} \\
175 \\
\\
183 \\
176 \\
200 \dagger \\
163 \ddagger \\
188 \S \\
189 \\
\\
197\end{array}$ & $\begin{array}{c}84 \cdot 4 \\
81 \cdot 2 \\
84 \cdot 9 \\
\text { Digita } \\
78 \cdot 5^{*} \\
74 \cdot 0 \\
\\
74 \cdot 0 \\
74 \cdot 0 \\
78 \cdot 0 \dagger \\
62 \cdot 0 \ddagger \\
74 \cdot 0 \S \\
84 \cdot 0 \\
75 \cdot 0 \\
\text { Per }\end{array}$ & $\begin{array}{c}2 \cdot 20 \\
2 \cdot 35 \\
2 \cdot 32 \\
\text { lis stopp } \\
2 \cdot 46^{*} \\
2 \cdot 35 \\
\\
2 \cdot 47 \\
2 \cdot 40 \\
2 \cdot 57 \dagger \\
2 \cdot 64 \ddagger \\
2 \cdot 51 \S \\
2 \cdot 24 \\
\\
2 \cdot 63 \\
\text { icardioly }\end{array}$ & $\begin{array}{c}29 \cdot 0 \\
32 \cdot 7 \\
32 \cdot 2 \\
\text { ed } \\
34 \cdot 6 * \\
32 \cdot 7 \\
30 \cdot 7 \\
30 \cdot 6 \\
25 \cdot 7 \dagger \\
30 \cdot 0 \ddagger \\
27 \cdot 9 \S \\
26 \cdot 0 \\
\text { sis } \\
\text { sis }\end{array}$ & $\begin{array}{l}1 \cdot 31 \\
1 \cdot 39 \\
1 \cdot 37 \\
1 \cdot 52 * \\
1.42 \\
\\
1 \cdot 47 \\
1 \cdot 46 \\
1 \cdot 53 \dagger \\
1 \cdot 57 \ddagger \\
1 \cdot 50 \$ \\
1 \cdot 33 \\
1.56\end{array}$ & $\begin{array}{l}1800 \\
1800 \\
1800 * \\
1800 \\
1800\end{array}$ & $\begin{array}{l}19 \\
20 \\
33 \\
\\
26 * \\
36 \\
29 \\
\\
18 \\
33 \dagger \\
37 \ddagger \\
38 \$ \\
39 \\
44 \|\end{array}$ & $\begin{array}{l}105 / 86 \\
118 / 80 \\
122 / 84 \\
130 / 90\end{array}$ \\
\hline
\end{tabular}

* After mercupurin diuresis.

$\dagger$ After high salt and unrestricted fluids.

‡ After 3 g. $\mathrm{NH}_{4} \mathrm{Cl}$ daily and 2 mercupurin suppositories weekly.

$\S$ After 2 c.c. mercupurin intravenously. $\quad$ || Without diuretics or other drugs.

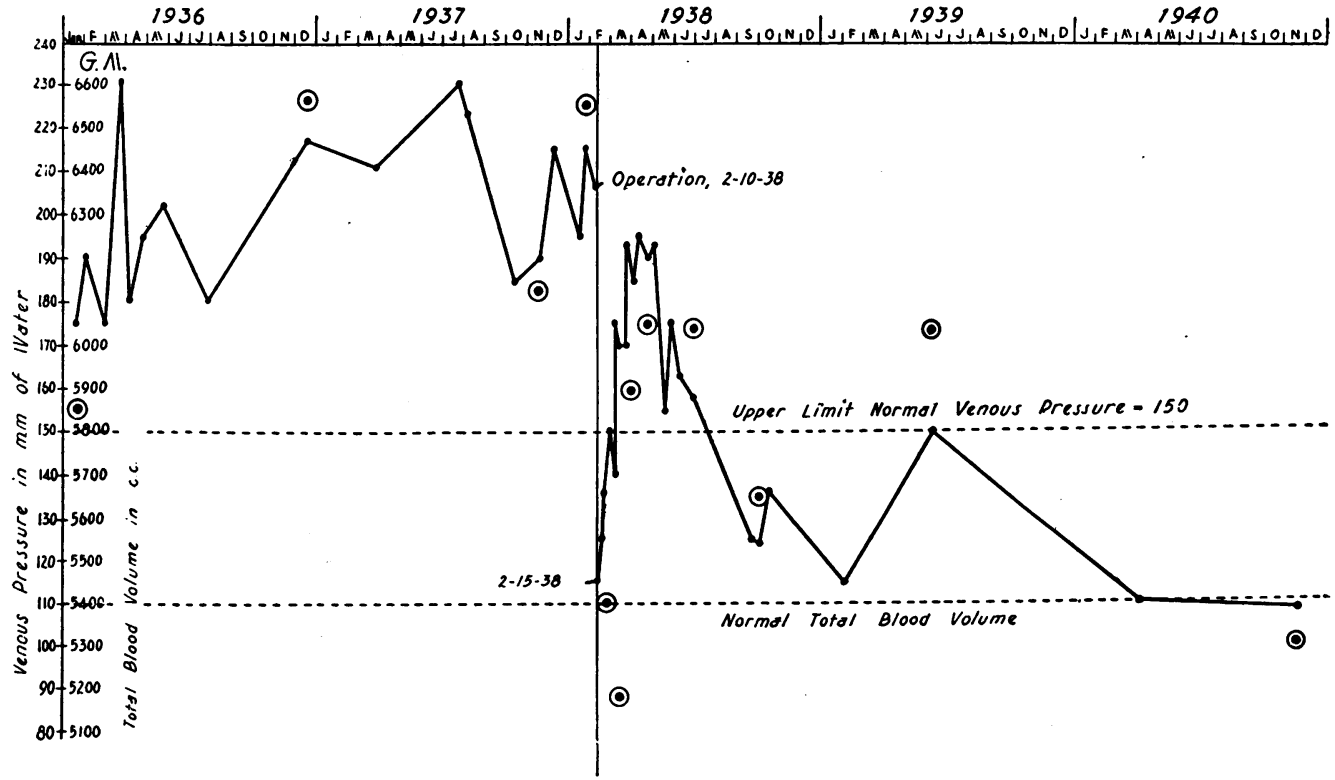

Fig. 1.-The course of the venous blood pressure and the total blood volume in Case 1 before and after pericardiolysis. 
In both patients the venous pressure decreased after operation so that it was within the normal range. Of special interest was the rise in venous pressure two weeks after the pericardiolysis in Case 1. This rise persisted for several months; the venous pressure then returned to normal. In this patient there was relatively little improvement in the cardiac output following operation, though the output per beat was somewhat greater and the heart rate was slower. In Case 2 studies of the cardiac output could not be carried out after the operation because of the severe constrictive pleuritis which limited his breathing (Burwell and Ayer, 1941).

Several interesting spontaneous variations in the circulatory dynamics of these patients were encountered. First, a close relationship between the changes in the blood volume and the changes in the venous pressure was noted in Case 1. This is shown graphically in Fig. 2.

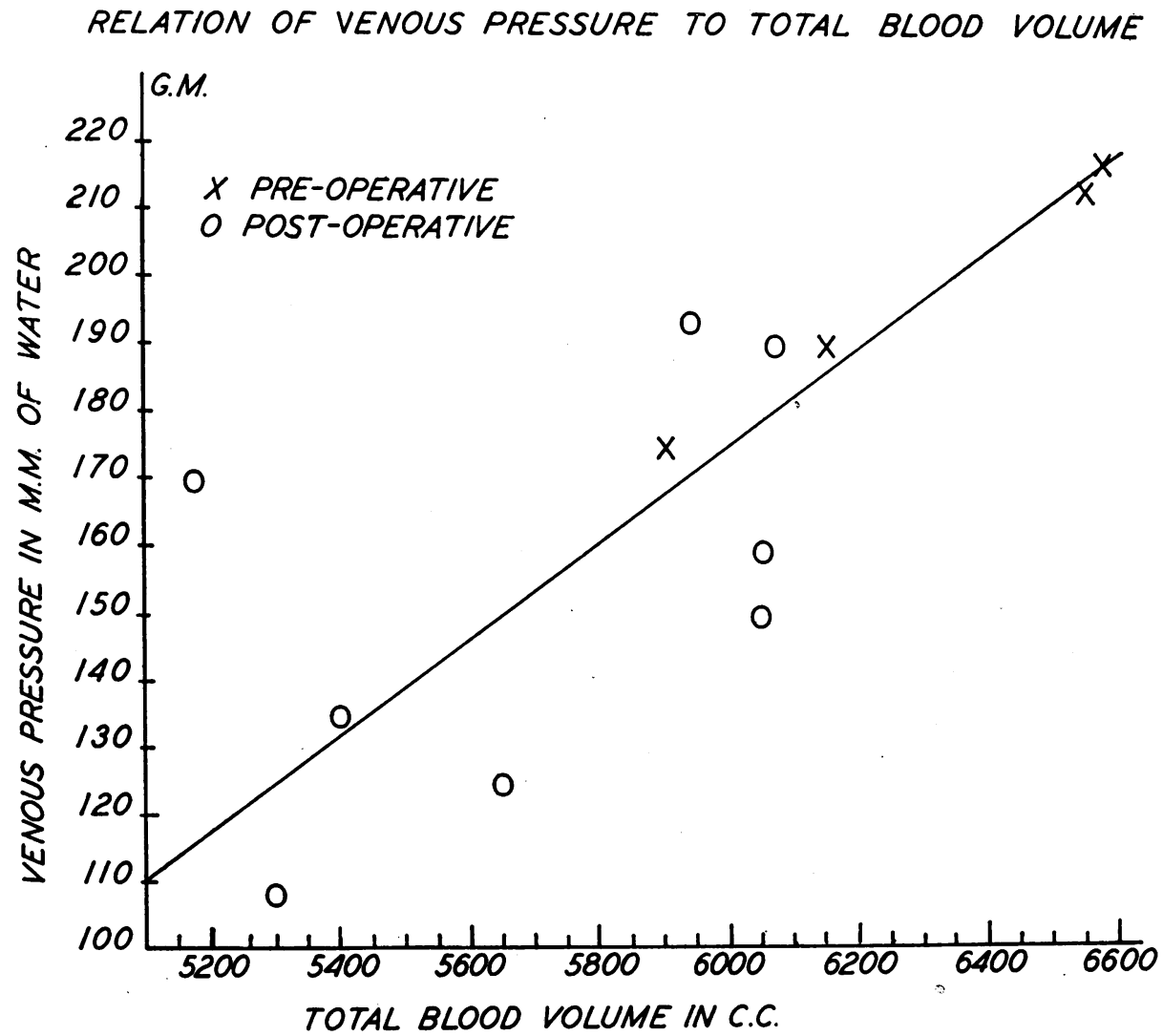

FIG. 2.-The relation of venous blood pressure to total blood volume in Case 1 .

The relation may be expressed as: V.P. $=-239+$ T.B.V. $(0.069) \pm 18.3 \mathrm{~mm}$. water. The correlation coefficient is $0.83 \pm 0.09$.

A similar relationship was apparent in Case 2, as seen in Table II. However, even with large spontaneous variations in venous pressure and blood volume no associated change was noted in the cardiac output per minute or per beat.

Second, there was considerable variation in the circulation time in both patients without corresponding change in the cardiac output or in the patients' general condition. In Case 1 a rough linear relationship was noted between the circulation time and the height of the venous pressure, as shown in Fig. 3. Case 2, who also had a high venous pressure and diminished cardiac output, usually had a prolonged circulation time but had several determinations within the normal range.

Third, when the heart rate increased there was a decrease in the output per beat in both patients. This was particularly evident in Case 2 who was completely digitalized at the start of his studies, and who showed a rise in heart rate when the digitalis was discontinued. The relationship between the heart rate and the output per beat is shown in Fig. 4 . In his case, 


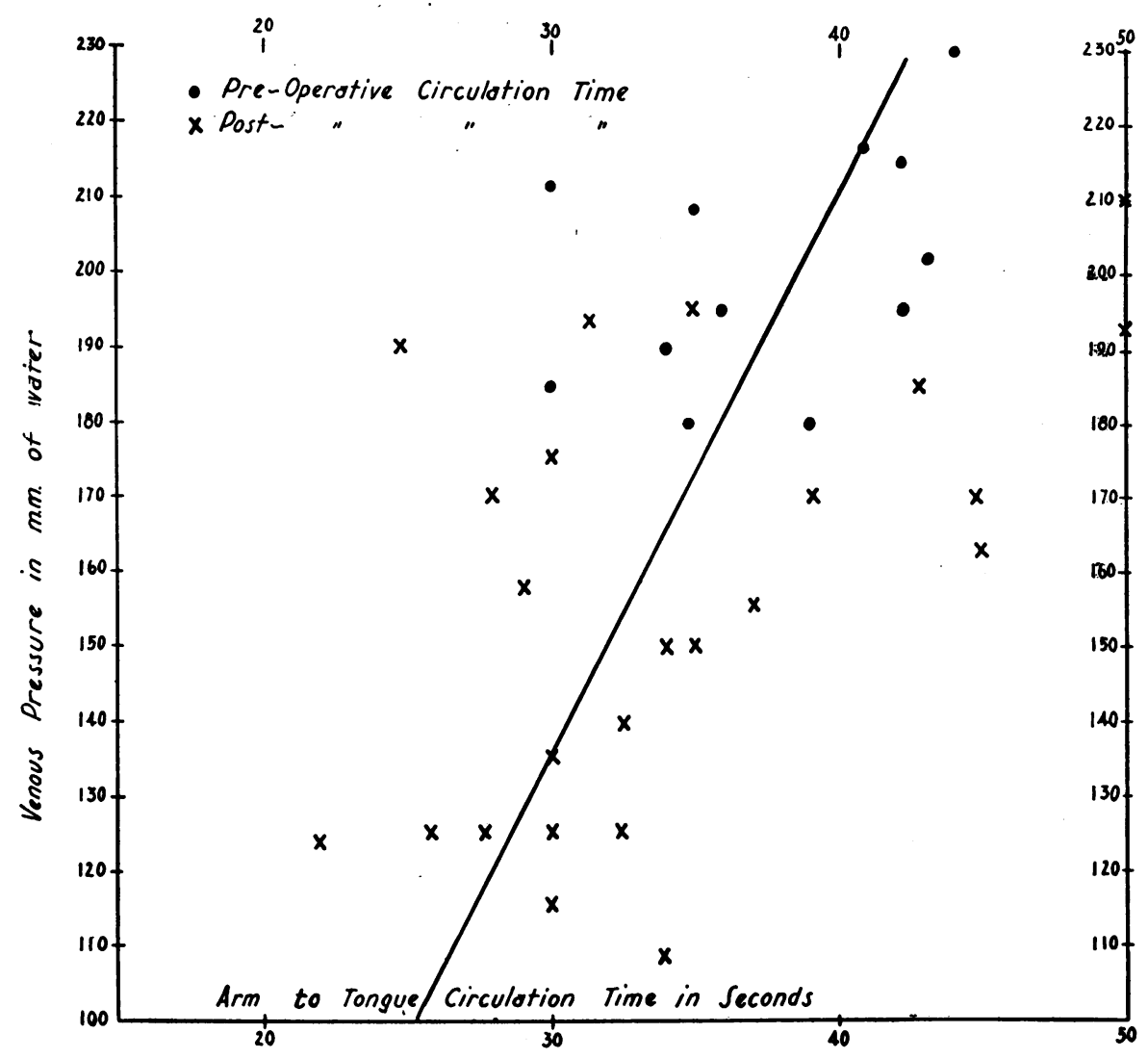

Fig. 3.-The relation of the circulation time and venous blood pressure in Case 1.

The relation could be expressed as: C.T. $=11 \cdot 86+$ V.P. $(0 \cdot 133) \pm 5.8 \mathrm{sec}$. The correlation coefficient is $0.58 \pm 0 \cdot 11$.

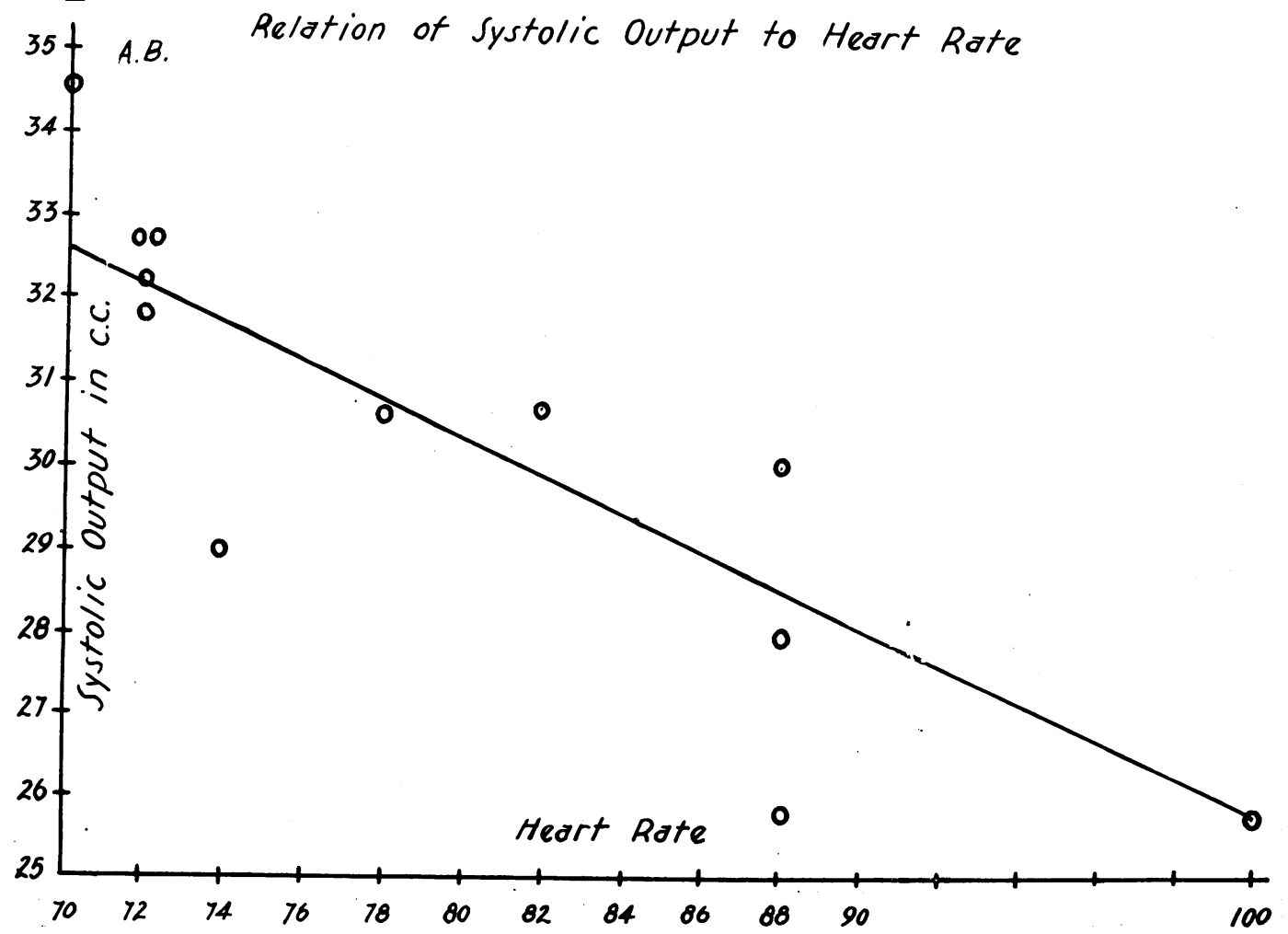

Fig. 4.-The relation of the heart rate and the output of the heart per beat in Case 2.

The relation may be expressed as: C.O./beat $=49 \cdot 1+$ heart rate $(-0 \cdot 235) \pm 1 \cdot 6$. The correlation coefficient is $0 \cdot 80 \pm 0 \cdot 11$. 
even though there was a decrease in the output per beat, the output per minute showed a slight but progressive increase with the increased heart rate (Fig. 5). The same type of

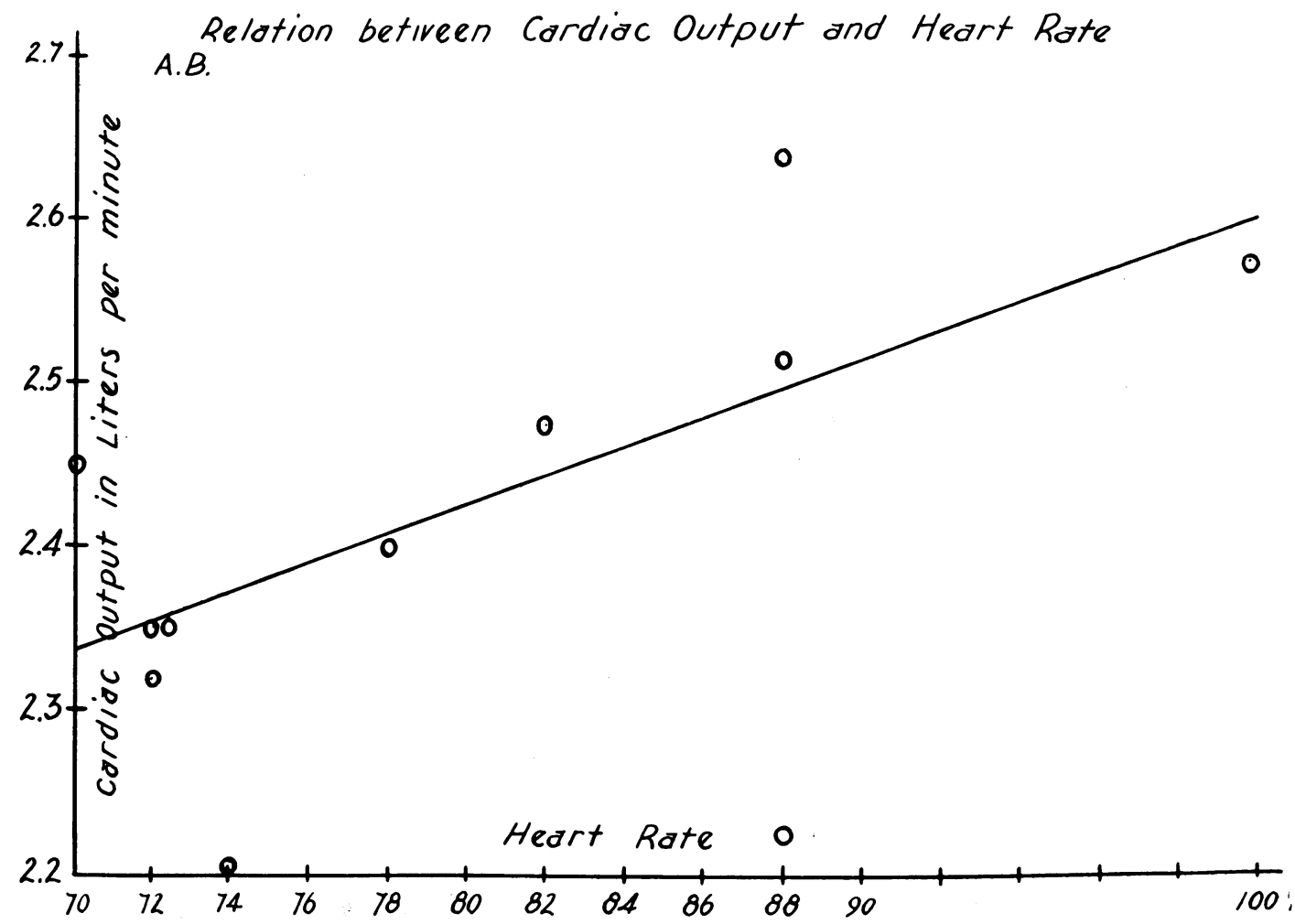

FIG. 5.-The relation of the heart rate and the output of the heart per minute in Case 2.

The relation may be expressed as: C.O./min. $=1717 \cdot 6+$ heart rate $(8 \cdot 78) \pm 112 \cdot 5$. The correlation coefficient is $0 \cdot 57 \pm 0 \cdot 2$.

change was apparent in Case 1 but there was less variation in the heart rate and the changes were not so pronounced.

To amplify the observations made under standard conditions the following special studies have been carried out.

\section{The Changes in the Circulation with Changes in Blood Volume}

It has been noted that there was a correlation between blood volume and venous pressure when spontaneous changes occurred. Such changes in blood volume and venous pressure were not reflected in alterations in heart rate or cardiac output. This observation led us to study the effect of rapidly induced changes in the blood volume.

After observing the effects of smaller amounts, 2900 c.c. of glucose and saline was administered by intravenous infusion in 45 minutes to Case 1. The results are recorded in Fig. 6. Although the venous pressure increased from 190 to $350 \mathrm{~mm}$. of water there was no significant change in the cardiac output per minute or per beat. The heart rate increased only from 72 to 80 . The circulation time was increased considerably at the middle of the infusion, and at the end of the infusion a 5 c.c. injection of sodium dehydrocholate failed to produce a reaction.

A similar infusion of 860 c.c. was administered to Case 2 in 15 minutes. There was a prompt increase in venous pressure from 185 to $325 \mathrm{~mm}$. of water with the first portion of the infusion, followed by a gradual rise to $335 \mathrm{~mm}$. with the last 150 c.c. In spite of a total rise of $150 \mathrm{~mm}$. in the venous pressure there was no significant change in the cardiac output per minute. The output per beat fell from 34.6 to $29 \cdot 7$ c.c., while the heart rate increased from 70 to 76 . 


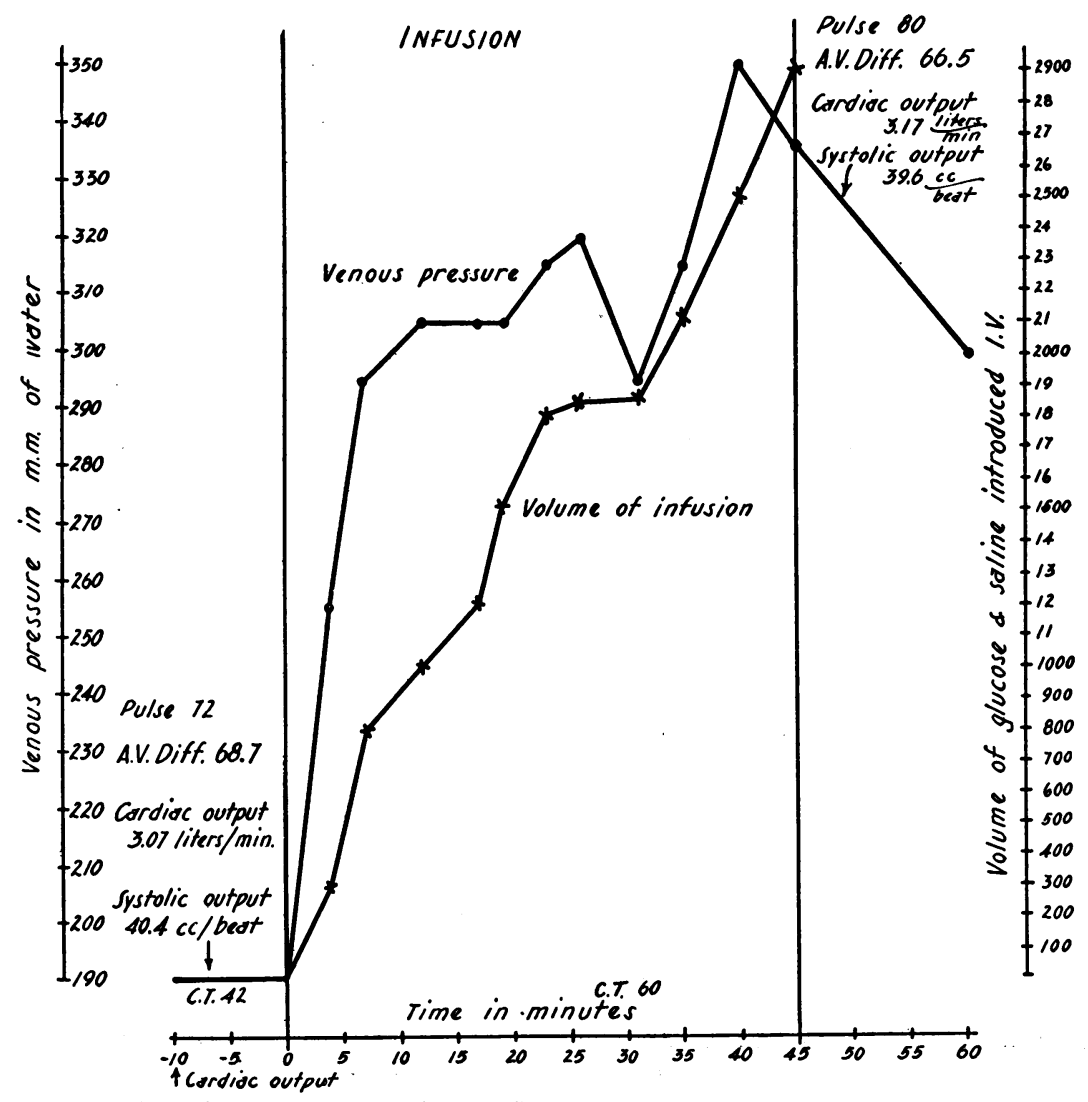

FIG. 6.-The effect of the intravenous infusion of fluid (5 per cent glucose in normal saline) on the venous pressure and on the output of the heart per minute and per beat, in Case 1.

Since a large increase in the venous pressure failed to alter the circulation significantly, the effect of induced decrease in venous pressure was then studied. After control measurements were made, blood (500 c.c.) was withdrawn over a twenty-minute period while the venous pressure, arterial pressure, and heart rate were observed. Immediately after the phlebotomy the cardiac output per minute and per beat were measured. The blood was then replaced and a third determination of the cardiac output made.

In Case 1 (see Fig. 7) there was a progressive fall in the venous pressure from 200 to $135 \mathrm{~mm}$. of water during the removal of the first 300 c.c. of blood. The removal of an additional 200 c.c. lowered the venous pressure only $5 \mathrm{~mm}$. further. The cardiac output per minute remained essentially unchanged. The heart rate changed from 72 to 76 . The output per beat decreased only from 49.0 c.c. to $47 \cdot 2$ c.c. The replacement of the blood was associated with a slow but progressive rise in the venous pressure during the introduction of the first half of the infusion, and a more rapid rise toward the end until the venous pressure was $193 \mathrm{~mm}$. of water. The patient, by this time, was somewhat disturbed by the long procedure. The oxygen consumption was elevated, the cardiac output was increased from 3.6 to 4.0 liters per minute, and the heart rate was 80 . The circulation time remained essentially unchanged during the entire period.

A similar study of phlebotomy was made on Case 2 with generally similar results (Fig. 8). In this case, however, the venous pressure fell only $30 \mathrm{~mm}$., from 215 to $185 \mathrm{~mm}$. of water. As with Case 1 the venous pressure decreased during the removal of the first 300 c.c. of blood and it remained unchanged with the removal of an additional 200 c.c. The cardiac output per minute and per beat actually increased somewhat at the end of the phlebotomy which may represent a slight change from the basal state. With the re-infusion of the blood the venous pressure increased rapidly and progressively to $275 \mathrm{~mm}$. The cardiac output, per minute and per beat, and the heart rate remained close to the initial determinations. 
Patient O.M.

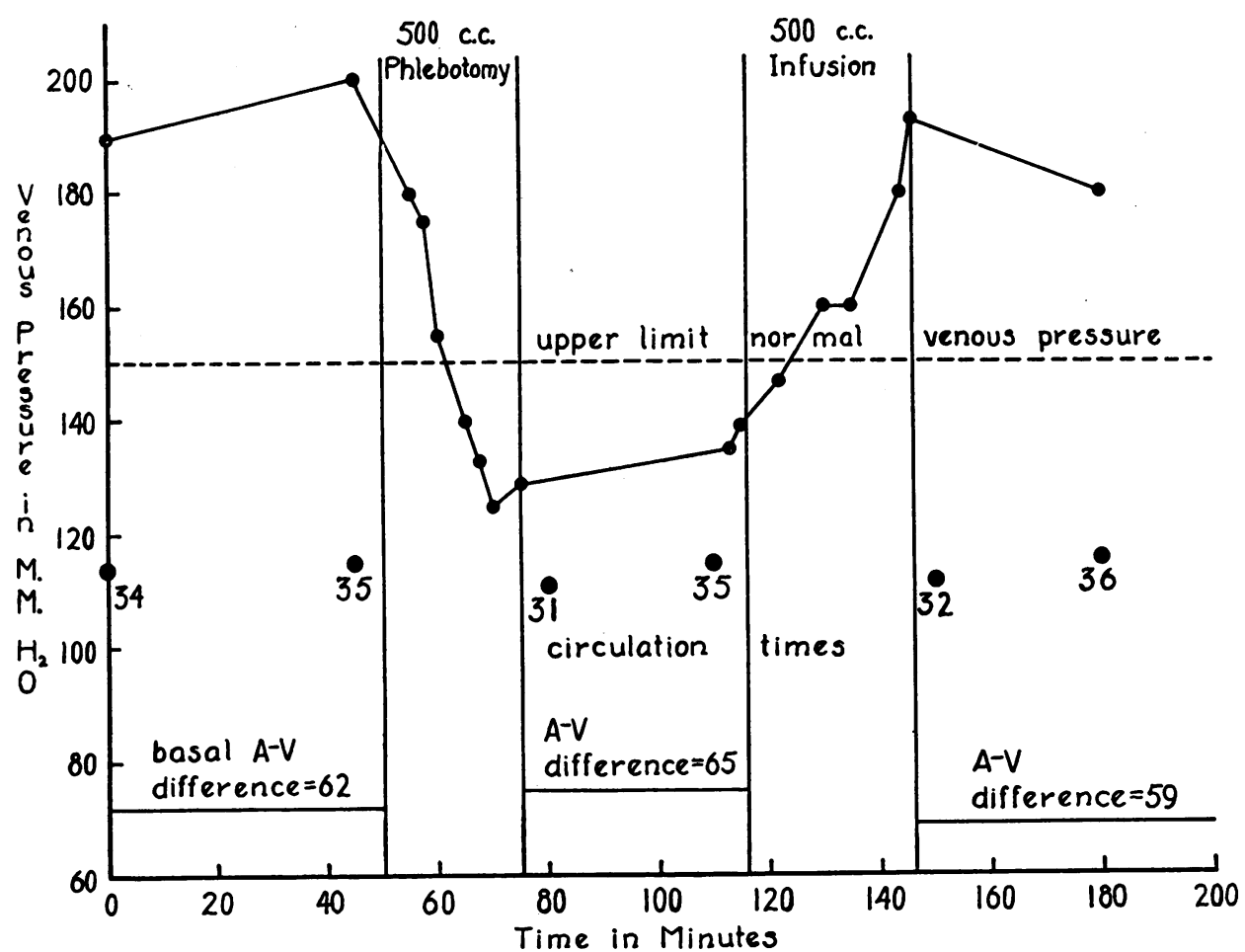

Fig. 7.-The effect of phlebotomy and re-infusion in Case 1 on the venous pressure, circulation time, and arterio-venous oxygen difference.

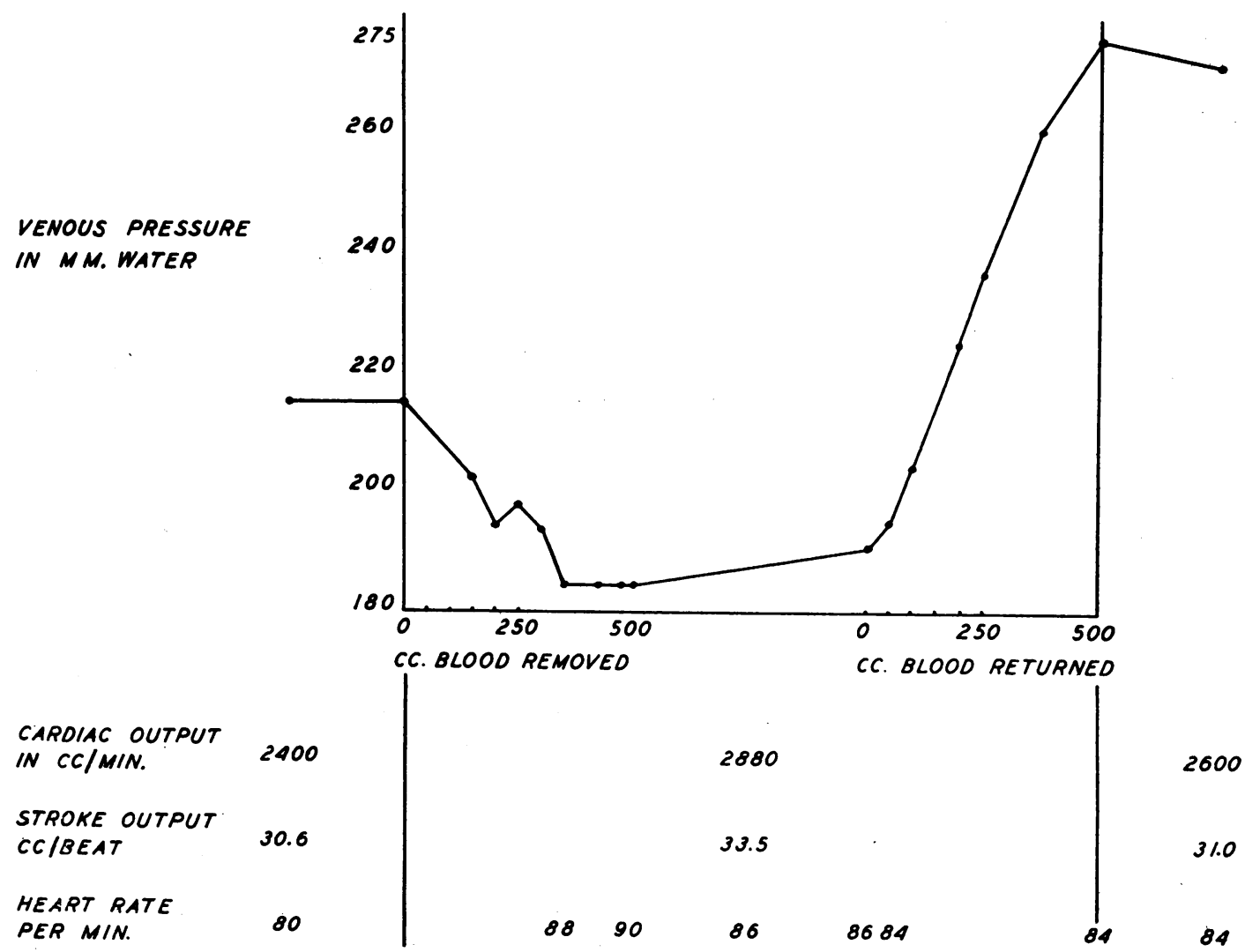

FIG. 8.-The effect of phlebotomy and re-infusion on the venous pressure, cardiac output per minute and per beat, and the heart rate in Case 2. 


\section{The Changes in the Circulation with Changes in Heart Rate}

It was noted in the studies of spontaneous variation that when the heart rate was increased there was a decrease in the output of the heart per beat. In spite of this the cardiac output per minute was increased by such tachycardia, especially in Case 2. To test these observations further a transient tachycardia was produced by the intravenous injection of atropine sulphate so that comparable measurements of the circulation could be made immediately before and during the rapid heart action.

. With Case 1 (Fig. 9), $3 \mathrm{mg}$. of atropine sulphate intravenously produced an increase in the

Patient G.M.

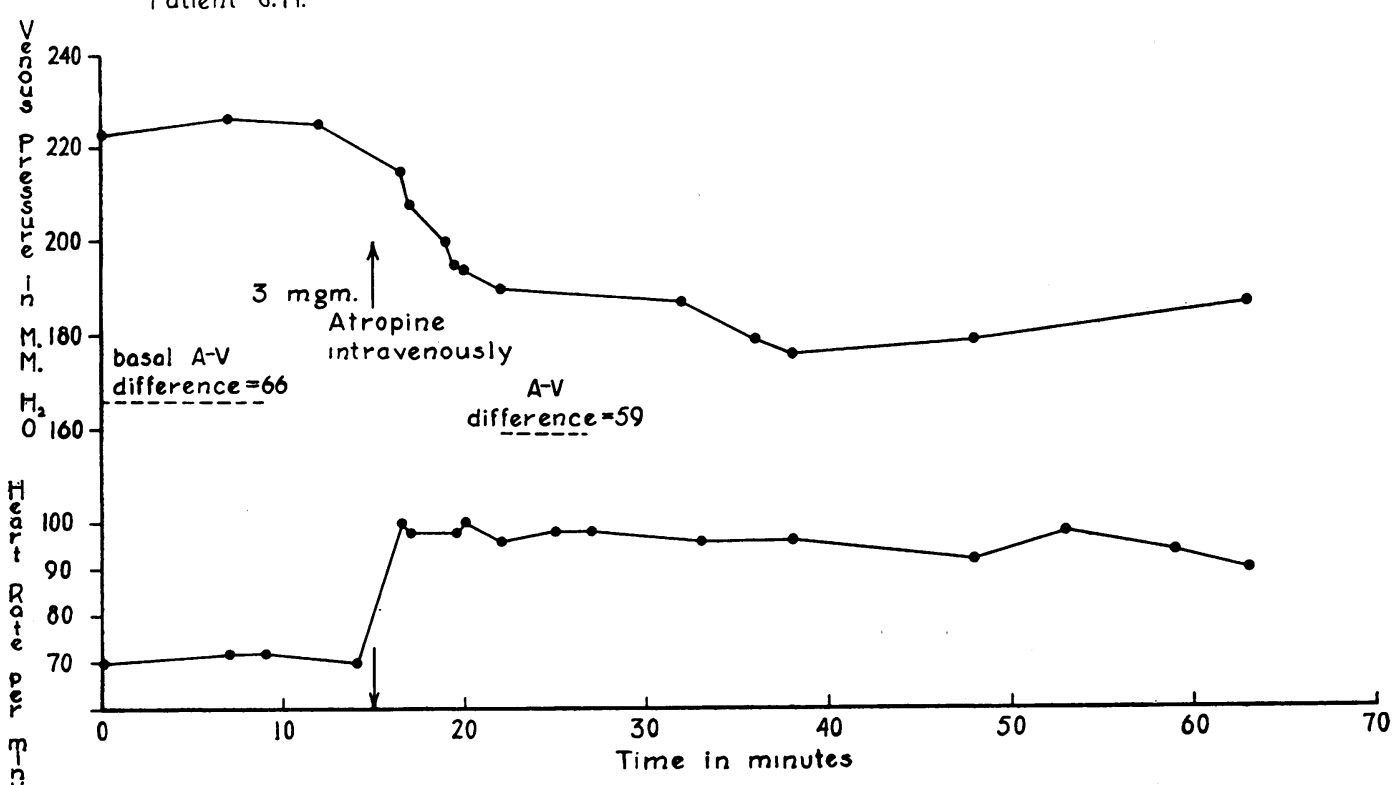

Fig. 9.-The effect of rapid rise in heart rate (induced by $3.0 \mathrm{mg}$. atropine sulphate intravenously) on the venous pressure and arterio-venous oxygen difference in Case 1.

heart rate from 70 to 98 . With the onset of the tachycardia there was a fall in the venous pressure from 225 to $177 \mathrm{~mm}$. of water, followed by a gradual return toward the control level as the tachycardia decreased. Although the output per beat decreased from 45 to 35 c.c., the output per minute was increased from 3.0 to 3.4 liters per minute. These observations were repeated a second time with essentially similar findings.

In Case $2,4 \mathrm{mg}$. of atropine sulphate produced an increase in the heart rate from 72 to 94 , and a fall in the venous pressure from 232 to $215 \mathrm{~mm}$. of water. Although the output per beat decreased from 33 to 27 c.c., there was an increase in the output per minute from 2.35 to 2.7 liters. At the same time there was a slight increase in the vital capacity from 1800 to 2000 c.c., and a decrease in the circulation time from 36 to 26 seconds.

The effect of tachycardia that follows exercise was studied in Case 1. Immediately after a standard exercise the changes in the venous pressure and heart rate were observed. Fig. 10 is representative of the changes. There is considerable elevation of both venous pressure and heart rate at the end of exercise and both fall promptly with rest. The increased heart rate, however, continues for a considerable time, and is accompanied by a fall in venous pressure to a point below the initial resting level.

\section{Discussion}

It is accepted that the principal circulatory defect in constrictive pericarditis is limitation of diastolic filling of the ventricles. This results in a diminution of the output per beat. This is usually sufficiently severe to bring about a decrease in the cardiac output per minute even though a compensatory tachycardia may be present. 
R. H. LYONS AND C. S. BURWELL

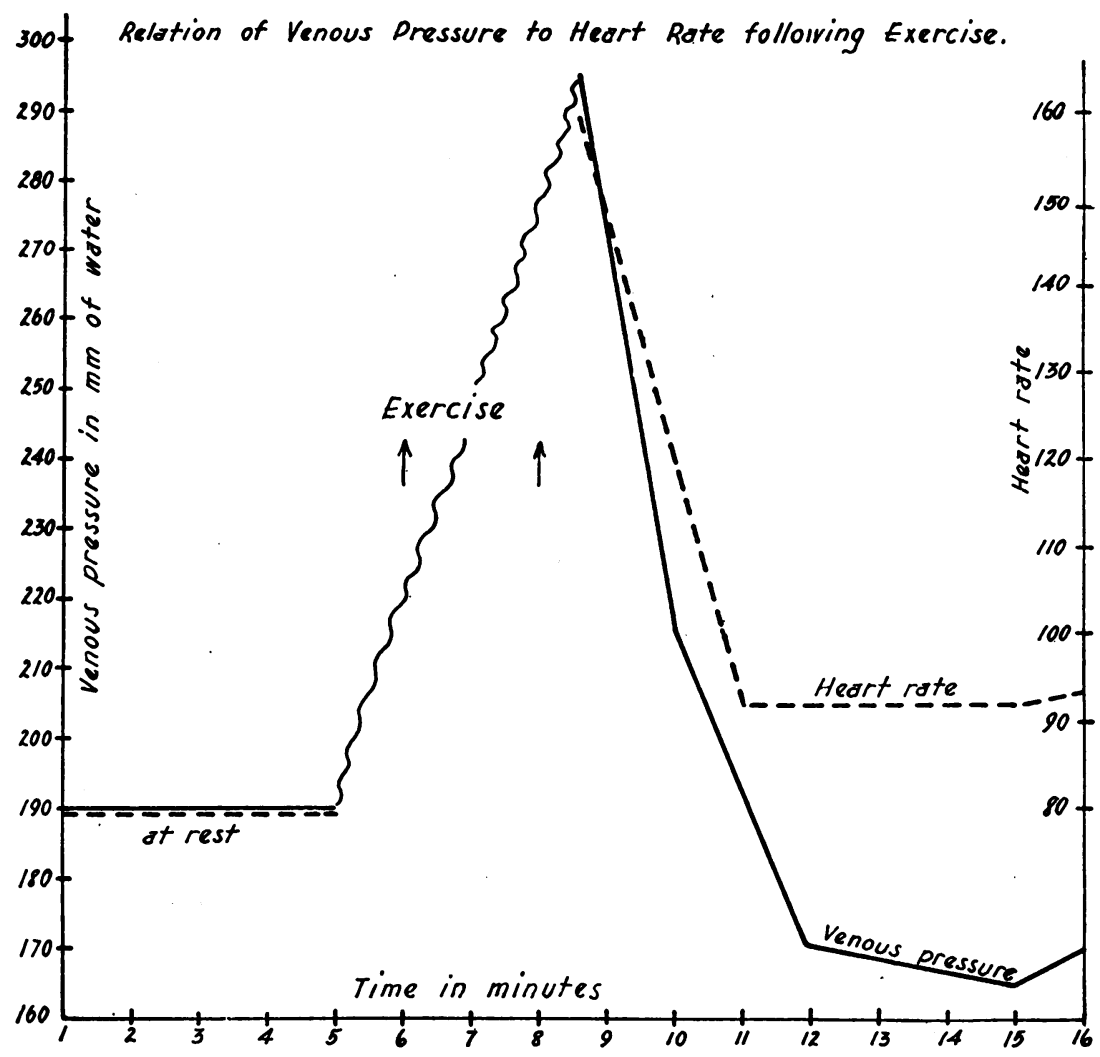

Fig. 10.-The effect of exercise on the venous pressure and heart rate of Case 1.

A question arises as to the effect of elevated venous pressure upon cardiac filling and cardiac output. When the heart is normal, a rise in venous pressure increases filling and output. What is the effect of such pressure change in the presence of pericardial obstruction? Where tamponade is due to pressure exerted by fluid in the pericardium (i.e. to a high intrapericardial pressure), an increase in venous pressure above some critical point may be expected to increase the flow of blood into the heart and so increase the cardiac output. This theoretical expectation is realized experimentally as is shown in a recent article by Cooper, Stead, and Warren (1944). Does the elevated venous pressure of constrictive pericarditis also assist in maintaining the circulation? It is apparent from our observations that large spontaneous variations of the venous pressure in these subjects have essentially no effect on ventricular filling as judged by alterations in the output per beat. Induced increases in the venous pressure of 160 and $150 \mathrm{~mm}$. of water respectively, as a result of rapid infusion of glucose and saline, also failed to alter significantly the output per beat, the heart rate, or the output per minute. Rapidly induced decreases in the venous pressure of 60 and $30 \mathrm{~mm}$. respectively also failed to affect the output per beat. That is, induced alterations in venous pressure over a total range of 220 and $180 \mathrm{~mm}$. of water in these two patients did not influence the volume of the cardiac output. The conclusion that the high venous pressure of constrictive pericarditis is not effective compensation is in accord with expectation, since the obstruction to filling is not a high pressure (which may be overcome) but a non-distensible scar which puts a limit to dilatation of the ventricle during diastole.

It should be mentioned that while there was a progressive fall in the venous pressure of both patients during the first 300 c.c. of the phlebotomy, the further removal of 200 c.c. of blood failed to induce corresponding changes in the venous pressure. This sudden change in rate of fall in venous pressure during phlebotomy implies the operation of some compensatory mechanism. It may be that venous constriction occurs at that level and tends to prevent a further fall in the pressure.

The wide fluctuation in the venous pressure noted in following the course of those patients 
appears to be related to changes in the volume of the blood and not directly related to changes in cardiac output. The elevation of the blood volume in these cases is similar in degree to that found in congestive heart failure and is probably due to similar mechanisms, one of which may be the abnormal retention of sodium. With such a retention of sodium either in normals (Lyons, Jacobson, and Avery, 1944) or in cardiacs, there is a resultant elevation of the blood volume and an increase in the venous pressure. The elevation of the venous pressure in Case 2 following the ingestion of large amounts of salt (Table II), and the fall in the venous pressure after ammonium chloride and mercupurin, suggest that the sodium balance may be an important factor in the control of venous pressure in such patients.

In most cases of constrictive pericarditis important manifestations are œdema, ascites, and pleural effusion. Presumably these result chiefly from the elevated venous pressure. These may be successfully influenced in the milder cases by a low sodium intake and occasional diuretics. In more severe cases the venous pressure cannot be lowered sufficiently to prevent the development of transudates, even with extensive diuresis.

The tachycardia noted in these subjects may well represent a mechanism tending to compensate for the diminished cardiac output per beat imposed by the limitation of diastolic filling. The increase in the cardiac output per minute and the decrease in venous pressure after induced tachycardia suggest that a rapid heart rate may be beneficial under these circumstances. Conversely a bradycardia may be injurious. Burwell and Strayhorn (1932) observed a patient in whom a decrease in the heart rate of 16 beats per minute, the result of digitalization, was associated with a fall in the cardiac output of 580 c.c. per minute. Similarly, in Case 2, the heart rate and cardiac output increased after digitalization was stopped. It is probable that digitalis has only an occasional place in the medical management of these patients with a regular rhythm, not only because of its effect on the heart rate, but also because it cannot alter the cardiac output through improvement in muscle tone since the heart is constricted rather than dilated. Exceptions to this rule may be found in patients with auricular fibrillation and many inefficient ventricular contractions, and in patients who have myocardial dilatation following relief of the constrictive pericarditis.

Increase in the heart rate is the only way in which these patients can increase the cardiac output (e.g. during exercise), since the associated elevation of the venous pressure fails to increase filling. The effect of tachycardia following exercise is similar to the effect of tachycardia produced by atropine in its ability to lower the venous pressure below the control level. This is not to say that an unlimited degree of tachycardia is desirable for these patients. There is probably an optimum rate in each individual, which is neither too high nor too low. Experience with patients having constrictive pericarditis and auricular fibrillation indicates that this optimum rate is considerably slower than the usual ventricular rate in uncontrolled auricular fibrillation.

\section{SUMMARY}

Observations of the alterations in venous pressure, blood volume, heart rate, cardiac output per beat and per minute, circulation time, and vital capacity have been recorded for one patient with constrictive pericarditis who was studied for three years prior to pericardiolysis and for six years after the operation. Similar observations have been made on another patient with a more profound disability for a shorter time.

The spontaneous fluctuations in the venous pressure in these patients were not related to alterations in the cardiac output per minute or per beat, but appeared to be closely correlated with variations in the blood volume. It appears likely, therefore, that such fluctuations in venous pressure in these patients reflect changes in the water content of the body.

Increases in venous pressure of 160 and $130, \mathrm{~mm}$. of water above the control level was produced in the two patients by the intravenous infusion of glucose and saline. These increases failed to alter the heart rate or the cardiac output per beat and per minute.

Decreases in the venous pressure of 60 to $30 \mathrm{~mm}$. of water as a result of a 500 c.c. phlebotomy also failed to alter the cardiac output per minute and per beat.

Spontaneous increases in the heart rate were associated with decreases in the output per 
beat, and with a slight net increase in the cardiac output per minute. Tachycardia produced by the intravenous injection of atropine sulphate was accompanied by an increase in the cardiac output per minute and a fall in the venous pressure. Tachycardia following exercise produced a similar decrease in the venous pressure below the resting level.

\section{REFERENCES}

Beck, C. S., and Cushing, E. H. (1934). J. Amer. med. Ass., 102, 1543.

$\longrightarrow$ and Griswold, R. A. (1930). Arch. Surg., 21, 1064.

Burwell, C. S., and Ayer, G.D. (1941). Amer. Heart J., 22, 267. and Blalock, A. (1938). J. Amer. med. Ass., 110, 265. and Flickinger, D. (1935). Arch. intern. Med., 56, 250.

and Strayhorn, W. D. (1932). Arch. Surg., 24, 106.

Cooper, F. W., Jr., Stead, E. A., Jr., and Warren, J.V. (1944). Ann. Surg. 120, 822.

Gibson, J. G. II, and Evelyn, K.A. (1938). J. Clin. Invest., 17, 153.

Grollman, A., Friedman, B., Clark, G., and Harrison, T. R. (1933). Ibid., 12, 751.

Lyons, R. H., Jacobson, S. D., and Avery, N. L. Jr. (1944). Amer. J. med., Sci., 208, 148.

, Kennedy, J. A., and Burwell, C. S. (1938). Amer. Heart J., 16, 675.

Maltby, A. B. (1934). Proc. Soc. Exper. Biol. Med., 31, 853.

Merrill, A. J. (1944). Read before Amer. Fed. for Clinical Research, Midwestern Section, Chicago, Ill.

Stewart, H. J., Heuer, G. J., Deitrick, J. E., Crane, N. F., Watson, R. F., and Wheeler, C. H. (1938). J. Clin. Invest., 17, 581 . 